\title{
Role of hysterolaparoscopy in the diagnosis and management of infertility
}

\author{
Saumya P. Agrawal ${ }^{1 *}$, Noopur Kedia ${ }^{1}$, Shashwat K. Jani ${ }^{1}$, Siddharth P. Agrawal ${ }^{2}$
}

${ }^{1}$ Department of Obstetrics and Gynecology, ${ }^{2}$ Student, NHL Municipal Medical College, Ahmedabad, Gujarat, India

Received: 23 January 2020

Accepted: 28 February 2020

\section{*Correspondence:}

Dr. Saumya P. Agrawal,

E-mail: saumyaagrawal31192@gmail.com

Copyright: () the author(s), publisher and licensee Medip Academy. This is an open-access article distributed under the terms of the Creative Commons Attribution Non-Commercial License, which permits unrestricted non-commercial use, distribution, and reproduction in any medium, provided the original work is properly cited.

\begin{abstract}
Background: Infertility is defined by WHO and ICMART as a disease of the reproductive system by the failure to achieve a clinical pregnancy after 12 months or more regular unprotected sexual intercourse. Objective of this study were to assess the role of hysteroscopy and laparoscopy in the evaluation of female infertility. To assess the therapeutic role of these endoscopic modalities in cases of infertility.

Methods: A prospective study of 112 women coming with the complain of infertility to a tertiary care centre hospital in Ahmedabad over a period of 30 months from January 2017 to June 2019.

Results: Of the 112 cases, $69.7 \%$ had primary infertility and $30.3 \%$ had secondary infertility. Septum was the most common hysteroscopic finding $(7.1 \%)$ followed by polyps $(5.4 \%)$ and synechiae $(3.6 \%)$. Adhesions was the most common laparoscopic finding $(23.2 \%)$ followed by tubal blocks $(19.7 \%)$ and fibroid $(17.9 \%)$. Polycystic ovaries were seen in $12.5 \%$ patients followed by endometriosis in $10.7 \%$ women. Myomectomy was most common therapeutic procedure (17.9\%) followed by adhesiolysis in $14.3 \%$ women and PCO drilling in $8.9 \%$ women.

Conclusions: Hysterolaparoscopy is useful as a diagnostic and therapeutic measure for women having infertility.
\end{abstract}

Keywords: Diagnosis, Hysterolaparoscopy, Infertility, Operative procedure

\section{INTRODUCTION}

Infertility is defined by WHO and ICMART as "a disease of the reproductive system by the failure to achieve a clinical pregnancy after 12 months or more regular unprotected sexual intercourse". ${ }^{1}$ The number of couples experiencing fertility problems has increased from $8 \%$ to $10-15 \% .^{2}$

The U. S. supreme court held in 1998 that infertility is a disability under the Americans with Disabilities Act (ADA) where disability means a physical or mental impairment that substantially limits one or more major life activities. ${ }^{3}$ Childlessness may be a tragedy to a married woman, and can be a cause of marital upset as well as of personal unhappiness and ill-health.
Infertility is of two types-primary and secondary infertility, primary infertility is the absence of live birth for women who desire a child and have been in a union for at least 12 months, during which they have not used any contraceptives. ${ }^{4}$ Secondary infertility refers to couples who have been able to get pregnant once (irrespective of the outcome), but now are unable. ${ }^{4}$

Over the past decade, significant advances have occurred in the diagnosis and treatment of reproductive disorders. The practice committee of the American Society for Reproductive Medicine (ASRM) has published guidelines for a standard infertility evaluation. It includes a semen analysis, assessment of ovulation, a hysterosalpingogram, and, if indicated, tests for ovarian reserve and laparoscopy., 5 The role of laparoscopy as an investigative procedure in infertility has changed over the 
past few years. Given that is allows direct visualization of the pelvic reproductive anatomy, it is the test of choice to identify otherwise unrecognized peritoneal factors that influence fertility, specifically, endometriosis and pelvic adhesions. Hysteroscopy has also played a similar role in diagnosis and treatment of cornual blocks, cornual polyps, intrauterine adhesions, intrauterine septa, submucous fibroids, etc. According to Lindemann et al, laparoscopy and hysteroscopy can be combined in one session to permit a full survey of the uterus and tubes and is useful in detecting the cause of infertility in female. ${ }^{7}$

In this study we aim to assess the role of hysteroscopy and laparoscopy in the evaluation of female infertility. To assess the therapeutic role of these endoscopic modalities in cases of infertility.

\section{METHODS}

This prospective study on the role of hysterolaparoscopy in the diagnosis and management of infertility was conducted at the department of obstetrics and gynecology at Smt NHL Municipal Medical College, Sheth Vadilal General Hospital, Ahmedabad, Gujarat, India during a period of 30 months from Jan 2017 to June 2019.

All the patients who satisfied the inclusion criteria and were willing to join the study were included in the study after they signed a consent form. A total of 112 patients were included.

\section{Inclusion criteria}

- Women married for $>1$ year

- Regular sexual intercourse

- Male factors found normal.

\section{Exclusion criteria}

- Any certified conception irrespective of site or outcome

- Any other medical or surgical disorders which precluded the use of hysterolaparoscopy as a diagnostic modality.

They were subjected to diagnostic hysterolaparoscopy to find out the causes of infertility. Any corrective surgical procedures if needed, were done in the same sitting.

\section{Statistical analysis}

Statically analysis was done using the software SSPS 16. All the categorical variables were expressed as proportions and incidence of each finding was calculated.

\section{RESULTS}

In the present study, out of 112 women, 78 infertile women had primary infertility and had never conceived during their lifetime whereas 34 had secondary infertility and had conceived before, irrespective of the pregnancy outcome (Table 1).

Table 1: Type of infertility.

\begin{tabular}{|lll|}
\hline & Primary infertility No. $(\%)$ & Secondary infertility No. (\%) \\
\hline Ahmed MS et al, ${ }^{8} \mathrm{n}=30$ & $21(70 \%)$ & $9(30 \%)$ \\
\hline Sachdev PK et al, ${ }^{9} \mathrm{n}=50$ & $34(68 \%)$ & $16(32 \%)$ \\
\hline Samal S et al, ${ }^{10} \mathrm{n}=100$ & $75(75 \%)$ & $25(25 \%)$ \\
\hline Present study, $\mathrm{n}=112$ & $78(69.75 \%)$ & $34(30.3 \%)$ \\
\hline
\end{tabular}

Table 2: Hysteroscopic findings.

\begin{tabular}{|lll|}
\hline Hysteroscopic findings & Present study $\mathbf{n = 1 1 2 , ~ N o . ~}(\%)$ & Prasanta KN et al ${ }^{\mathbf{1 1}} \mathbf{n}=\mathbf{3 0 0 ,}$ No. $(\%)$ \\
\hline Normal & $90(80.3 \%)$ & $244(81.3 \%)$ \\
\hline Myoma (submucous) & $2(01.8 \%)$ & $8(02.6 \%)$ \\
\hline Polyp & $6(05.4 \%)$ & $16(05.3 \%)$ \\
\hline Septum & $8(07.1 \%)$ & $29(9.6 \%)$ \\
\hline Synechiae & $4(03.6 \%)$ & $1(00.3 \%)$ \\
\hline Cervical stenosis & $2(01.8 \%)$ & $0(00 \%)$ \\
\hline
\end{tabular}

On hysteroscopy, 90 women had normal findings, 2 had submucous myoma, 6 had polyp, 8 had intrauterine septum, 4 had synechiae and 2 had cervical stenosis (Table 2).
On laparoscopy, 42 women had normal findings, 22 had tubal blocks, 12 had simple/complex ovarian cysts, 14 had polycystic ovaries, 10 had PID, 26 had adhesions, 20 had fibroids, 12 had endometriosis and 2 woman had uterine anomaly (Table 3). 
Table 3: Laparoscopic findings.

\begin{tabular}{|c|c|c|c|}
\hline Laparoscopic findings & $\begin{array}{l}\text { Present study } \\
\mathrm{n}=112, \text { No. }(\%)\end{array}$ & $\begin{array}{l}\text { Ramalingappa } \mathrm{C} \text { et al, }{ }^{13} \\
\mathrm{n}=668, \text { No. }(\%)\end{array}$ & $\begin{array}{l}\text { Prasanta KN et al, }{ }^{11} \\
\mathrm{n}=\mathbf{3 0 0}, \text { No. }(\%)\end{array}$ \\
\hline Normal & $42(37.5 \%)$ & $270(40.4 \%)$ & $199(66.3 \%)$ \\
\hline Unilateral tubal block & $16(14.3 \%)$ & $30(04.5 \%)$ & $30(10.0 \%)$ \\
\hline Bilateral tubal block & $6(05.4 \%)$ & $25(03.7 \%)$ & $31(10.3 \%)$ \\
\hline Ovarian cysts & $12(10.7 \%)$ & \multirow{2}{*}{$184(27.5 \%)$} & \multirow{2}{*}{$22(07.3 \%)$} \\
\hline PCO & $14(12.5 \%)$ & & \\
\hline Pelvic inflammatory disease & $10(08.9 \%)$ & $72(10.8 \%)$ & - \\
\hline Adhesions & $26(23.2 \%)$ & $128(19.2 \%)$ & $26(08.7 \%)$ \\
\hline Fibroid uterus & $20(17.9 \%)$ & $42(06.3 \%)$ & $15(05.0 \%)$ \\
\hline Endometriosis & $12(10.7 \%)$ & $59(08.8 \%)$ & $37(12.3 \%)$ \\
\hline Anomaly & $2(01.8 \%)$ & $12(01.8 \%)$ & $3(01.0 \%)$ \\
\hline
\end{tabular}

Table 4: Operative procedures performed.

\begin{tabular}{|lll|}
\hline Procedure & Present study $\mathbf{n}=\mathbf{1 1 2}$, No. $(\%)$ & Vaid K et al ${ }^{14} \mathbf{n}=\mathbf{1 9 3}$, No. (\%) \\
\hline PCO drilling & $10(08.9 \%)$ & $10(05.2 \%)$ \\
\hline Ovarian cystectomy & $4(03.6 \%)$ & $2(01.0 \%)$ \\
\hline Adnexal adhesiolysis & $16(14.3 \%)$ & $71(36.8 \%)$ \\
\hline Fulgration of endometriotic spots & $2(01.8 \%)$ & $29(15.0 \%)$ \\
\hline Salphingectomy & $6(05.4 \%)$ & $2(01.0 \%)$ \\
\hline Tubal cannulation & $4(03.6 \%)$ & - \\
\hline Fimbrioplasty & $4(03.6 \%)$ & $50(25.9 \%)$ \\
\hline Lap/hys myomectomy & $20(17.9 \%)$ & - \\
\hline Hys septal resection & $2(01.8 \%)$ & $4(02.1 \%)$ \\
\hline Hys polypectomy & $2(01.8 \%)$ & $10(05.2 \%)$ \\
\hline
\end{tabular}

Table 5: Intraoperative and postoperative complications in cases of hyterolaparoscopy.

\begin{tabular}{|l|l|}
\hline Complications & \multicolumn{1}{c|}{$\begin{array}{l}\text { Present study } \\
\mathbf{n}=\mathbf{1 1 2}, \text { No. (\%) }\end{array}$} \\
\hline Anaesthetic complications \\
\hline Nausea, vomiting & $12(10.7 \%)$ \\
\hline Hypercarbia & - \\
\hline Intra-operative complications \\
\hline Bleeding at cervix bite site & - \\
\hline Uterine perforation & - \\
\hline Injury to bowel & - \\
\hline Injury to bladder & - \\
\hline Post-operative complications \\
\hline Vomiting & $18(16.1 \%)$ \\
\hline Hemorrhage & - \\
\hline Fever & $12(10.7 \%)$ \\
\hline Paralytic ileus & - \\
\hline Wound infection & $2(01.8 \%)$ \\
\hline
\end{tabular}

Of the pathologies which were correctible, operative procedure was done in the same sitting. PCO drilling was done in 10 women, ovarian cystectomy in 4, adnexal adhesiolysis in 16 , fulguration of endometriotic spots in 2, salpingectomy in 6, tubal cannulation in 4, fimbrioplasty in 4 , myomectomy in 20 , hysteroscopic septal resection in 2 and hysteroscopic polypectomy in 2 (Table 4).

Intraoperative complications like uterine perforation, injury to bowel and bladder were not seen in any case. Post-operative vomiting was seen in 18 women, fever was seen in 12 women, wound infection was seen in 2 women (Table 5).

\section{DISCUSSION}

In the present study, $69.7 \%$ infertile women had primary infertility whereas $30.3 \%$ had secondary infertility. The results seen were comparable to studies done by Ahmed MS et al, Sachdev PK et al, and Samal S et al, having primary infertility in $70 \%, 68 \%$ and $75 \%$ women respectively (Table 1$).{ }^{8-10}$

In the present study, $80.3 \%$ women had normal hysteroscopic findings, $1.8 \%$ had submucosa fibroids, $5.4 \%$ had endometrial polyps, $7.1 \%$ had septate uterus, $1.8 \%$ had synechiae, $1.8 \%$ had cervical stenosis, with overlapping of findings in some cases. In the patient having cervical stenosis, further hysteroscopy to evaluate the endometrium could not be done. The results were comparable to Prasanta KN et al, study, where $81.3 \%$ women had normal hysteroscopic findings, $2.6 \%$ had myomas, $5.3 \%$ had polyps, $9.6 \%$ had septum's, $0.3 \%$ had 
synechiae (Table 2). ${ }^{11}$ The most common abnormality found was a septum, followed by a polyp. A septum distorts the uterine cavity and has poor blood supply, resulting in poor implantation efficiency and embryo growth. ${ }^{12}$ Large polyps also distort the cavity, and cause local inflammatory changes. Sperm transport and implantation of blastocyst is hampered in cases of submucous fibroids due to deformity of cavity, obstruction of ostia, and impaired uterine blood flow. Submucous myomas may displace the cervix, decreasing exposure to sperm. ${ }^{12}$

In the present study, $37.5 \%$ women had normal laparoscopic findings, $19.7 \%$ had tubal blocks on chromopertubation, out of which $14.3 \%$ were unilateral and $5.4 \%$ were bilateral. Ovarian cysts were seen in $10.7 \%$ cases and PCO was seen in $12.5 \%$ cases. PID was found in $8.9 \%$ cases, $23.2 \%$ had adhesions, $17.9 \%$ had fibroids, $10.7 \%$ had endometriosis, and $1.8 \%$ had uterine anomaly (with overlapping of findings in some cases). The results were comparable to the studies done by Ramalingappa $\mathrm{C}$ et al and Prasanta KN et al, (Table 3). ${ }^{11,13}$ Distal tubal blocks exhibit a wide spectrum of severity ranging from adherent fimbrial folds, to varying degrees of phimosis, to complete obstruction with hydrosalpinges. Proximal tubal blocks are caused by obliterative luminal fibrosis, salpingitis isthmica nodosa, chronic inflammation, and intratubal endometriosis. ${ }^{12}$ In the present study, most common abnormality was the presence of ovarian cysts and polycystic ovaries which result in infertility mainly due to anovulation. Intramural fibroids can cause dysfunctional uterine contractility and endometrial vascular disturbance and inflammation interfering with gamete transport and embryo implantation. ${ }^{12}$ Endometriosis, PID, adnexal adhesions distort the adnexal anatomy preventing ovum capture after ovulation and cause chronic inflammation leading to disorders of folliculogenesis, fertilization or implantation. $^{12}$

In the present study, apart from diagnostic use of infertility, hysteroscopy was used for myomectomy of submucous fibroid (1.8\% cases), septal resection $(1.8 \%$ cases) and polypectomy ( $1.8 \%$ cases). Laparoscopy was used for PCO drilling in $8.9 \%$ cases, cystectomy in $3.6 \%$ cases, adhesiolysis in $14.3 \%$ cases, fulgration of endometriotic spots in $1.8 \%$ cases, salphingectomy in $5.4 \%$ cases, unilateral tubal cannulation followed by selective chromopertubation in $3.6 \%$ cases, fimbrioplasty in $3.6 \%$ cases, and myomectomy in $16.1 \%$ cases. The results were comparable to the study done by Vaid $\mathrm{K}$ et al, (Table 4). ${ }^{14}$ More than one procedure was performed in some cases.

Hysterolaparoscopy has very few complications. Intra operative complications like uterine perforation, injury to bowel and bladder were not seen in any case. Postoperative vomiting was seen in $16.1 \%$ cases, pyrexia in $10.7 \%$ cases and wound infection in $1.8 \%$ cases. Zhang E et al evaluated the effects and safety of combined hysterolaparoscopy in diagnosing infertility and found no major surgical or anaesthetic complication in any of the 132 patients other than mild abdominal pain. ${ }^{15}$

Funding: No funding sources

Conflict of interest: None declared

Ethical approval: The study was approved by the Institutional Ethics Committee

\section{REFERENCES}

1. Zegers-Hochschild F, Adamson GD, De Mouzon J, Ishihara $\mathrm{O}$, Mansour $\mathrm{R}$, Nygren $\mathrm{K}$, et al. The International Committee for Monitoring Assisted Reproductive Technology (ICMART) and the World Health Organization (WHO) Revised Glossary on ART Terminol. 2009;92(5).

2. Resolve, The National Infertility Association, "National Survey of Family Growth, CDC, 20062010". Available at: https://resolve.org/infertility101/what-is-infertility/fast-facts/. Accessed on $3^{\text {rd }}$ June 2019.

3. Fertility within reach: Advocating for fertility health benefits, 2019. Available at: http://www.fertilitywithinreach.org/about. Accessed on $2^{\text {nd }}$ June 2019.

4. Health Information from the National Library of Medicine, 2018. Available at: Retrieved from https://medlineplus.gov. Accessed on $2^{\text {nd }}$ June 2019.

5. The Practice Committee of the American Society for Reproductive Medicine. Fertil Steril. 2015:00150282. Available at: http://dx.doi.org/10.1016/j.fertnstert.2014.12.103. Accessed on $2^{\text {nd }}$ June 2019.

6. Gianaroli L, Racowsky C, Geraedts J, Cedars M, Makrigiannakis A, Lobo LA. Best practices of ASRM and ESHRE: a journey through reproductive medicine. Fertil Steril. 2012;98(6):0015-0282.

7. Mohr J, Lindemann HS. Hysteroscopy in the infertile patients. J Reprod Med. 1977;19(3):161-2.

8. Ahmed MS, Bhalerao AN. Role of diagnostic hysterolaparoscopy in evaluation of female infertility. Int J Reprod Contracept Obstet Gynecol. 2017;6(9):4048-51.

9. Sachdeva PK, Kaur N. Role of hysterosalpingography and diagnostic laparoscopy in infertility. Int J Reprod Contracept Obstet Gynecol. 2016;5(11):3743-9.

10. Samal S, Agrawal S, Agrawal M. Role of laparoscopy in infertility in a rural setup hospital. Int J Reprod Contracept Obstet Gynecol. 2014;3(1):1858.

11. Nayak PK, Mahapatra PC, Mallick JJ, Swain S, Mitra S, Sahoo J. Role of diagnostic hysterolaparoscopy in the evaluation of infertility: a retrospective study of 300 patients. J Hum Reprod Sci. 2013;6(1):32-34.

12. Female infertility: an approach to the problem of infertility. The proper diagnostic tests and their correct interpretations, Chapter 17. In: Marc A. Fritz 
and Leon Speroff. Clinical Gynecologic Endocrinology and Infertility. ${ }^{\text {th }}$ ed. South Asian edition: Wolters Kluwer; 2016:1173-1175.

13. Antaratani RC, Harsha B. Hysterolaparoscopy in the evaluation and management of female infertility. Int J Reprod Contracept Obstet Gynecol. 2017;6(10):4454-7.

14. Vaid K, Mehra S, Verma M, Jain S, Sharma A, Bhaskaran S. Pan endoscopic approach "hysterolaparoscopy" as an initial procedure in selected infertile women. J Clin Diagn Res. 2014;8(2):95-8.
15. Zhang E, Zhang Y, Fang L, Li Q, Gu J. Combined hysterolaparoscopy for the diagnosis of female infertility: a retrospective study of 132 patients in China. Mater Sociomed. 2014;26(3):156-7.

Cite this article as: Agrawal SP, Kedia N, Jani SK, Agrawal SP. Role of hysterolaparoscopy in the diagnosis and management of infertility. Int J Reprod Contracept Obstet Gynecol 2020;9:1585-9. 